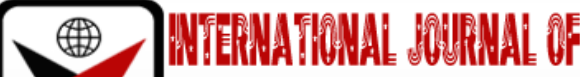

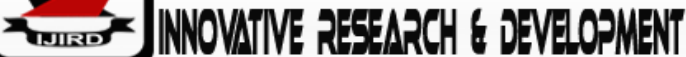

ISSN 2278 - 0211 (Online)

\section{Comparison of Biogas Production from Water Hyacinth and Poultry Waste}

Ibeawuchi Comfort
Researcher, Center for Occupational Health and Safety,
University of Port Harcourt, Nigeria
Utibe Daniel
Senior lecturer, Department of Animal and Environmental Biology
Institution name: University of Port Harcourt, Nigeria
Amadi Maxwell Chibuike
Researcher, Department of Animal and Environmental Biology
University of Port Harcourt, Nigeria

\begin{abstract}
:
The study examined the comparison of biogas production using water hyacinth and poultry waste. The organic wastes: poultry dung and water hyacinth were dried and digested in an anaerobic biodigester in a slurry form. Biogas productions were observed and measured for a stretch of 14 days. Temperature fluctuations and pH changes in the digester were monitored throughout the period. Heat efficiency and cooking rate of both substrates were also determined and compared with conventional gas (group). The result showed that temperature was within mesophilic temperature $\left(28^{\circ} \mathrm{C}-32^{\circ} \mathrm{C}\right)$. Also, the $\mathrm{pH}$ fluctuated within 6.0-7.4 which is an optimal range for methanogens responsible for biodigestion to thrive. The results further revealed that the total gas yield was $316.6 \mathrm{ml}$ and $209.0 \mathrm{ml}$ for poultry waste and water hyacinth respectively. A domestic heating test was carried out for the 2 substrates digested using the biogas produced to raise $300 \mathrm{ml}(0.3 \mathrm{~kg})$ of water to boiling point $\left(100^{\circ} \mathrm{C}\right)$. The time expended was recorded in minutes as follows - 8.56mins and 7.53mins for water hyacinth and poultry dung. In comparison, conventional gas (control) was faster than both substrates, while poultry waste was faster than water hyacinth in relation to time taken to raise the temperature of $0.3 \mathrm{~kg}$ of water to boiling point $\left(100^{\circ} \mathrm{C}\right)$. The research affirmed that poultry dung had the utmost gas turnout compared with water hyacinth, though it is more abundant for use as feedstock in this region. The research elucidates that the aquatic macrophytes (Eicchorniacrasssipes) and poultry waste can be transformed to profitable resource (biogas) which can help increase the energy stock and create wealth.
\end{abstract}

Keywords: Biogas, water hyacinth, poultry waste, substrate, fluctuation

\section{Introduction}

Among the challenges facing Nigeria as it is hoping to join developed countries in the world, is the perplexity of wastes that are littered around the cities and rural areas, not only defacing the allure of the country but also affecting livelihood, as some have health and economic implications. Yet, this may be a veiled gift in disguise if Nigeria could exploit the conversion of part of these wastes into meaningful products. Unfortunately, unlike what is tenable in other developed countries where waste is being converted, Nigeria still does not harness waste products. Agricultural and biomass waste characterize the chunk of waste spurned in the mostly agrarian society which Nigeria is. Take water hyacinth for example, this plant thrives in water channels in riverside areas, where it has gained notoriety as a weed which doomed to be removed for no intended use. Water hyacinths are proving too difficult to be eradicated completely because they rapidly adapt and regenerate upon perturbation. Being a nutrient dense plant, their biodegradation conduce ecosphere pollution as is their thriving life from them. Again, with the ban on importation of poultry products, the poultry industry in Nigeria is gradually positioning itself in the provision of animal protein in the local market, and with this comes the peril of managing the tons of biological waste produced. However, these wastes if exploited resourcefully possibly will be practical in one way or many others just like other wastes that have been converted to useful products.

Energy is not the only challenge facing the modern man, there is also the urgency to bear up the quantum of waste generated by humans and industries. Organic waste described as waste which can decompose and degrade so they be consumed as compost belong to a category of waste from which some profit can be derived (Sutarti et al., 2019). Using organic wastes which are never in short supply, as they can be by-product of households, industrial, agricultural, commercial and sundry other ventures, as renewable energy source has been hyped as ingenious way to tackle these twin problems, albeit with some merit. 
There is no denying the facts that plant biomass presents a pool of macromolecules that can be digested to yield energy in a sustainable manner. Nigeria a majorly agrarian society produced a large mass of agricultural wastes which can be harnessed to meet her energy need (Oladeji et al, 2009). Aquatic plants that meet the criteria for bioenergy production have the advantage of not competing with crop plants for land space, and have proven useful as feedstock for biofuel production (Rezania et al., 2015). Water hyacinth, a free-floating perennial aquatic weed, grows luxuriously in river courses in West African states, including Nigeria. This plant can be exploited for their biotechnological importance as a way to eradicate their nuisance value, as it is acknowledged to create impassable barriers that make navigation a nightmare and also cause socio-economic loses and ecological impairment.

Poultry waste which consists of faeces, urine, feather, and food droppings is lush with organic stock, nitrogen and phosphorus, which if discharged into the aquatic environment will eminently impact the receiving surrounding (Liu et al., 2018). Unlike in the northern section of Nigeria where cow is reared and their dung suggested for use in biogas making, the southern part of Nigeria has a burgeoning poultry industry that generate lots of wastes which can find commensurate application in biogas production. Nigeria is tagged the poverty nucleus of the world with poverty, a tag which does not befit a state with huge agricultural potential. Basically, with the quantum of water hyacinth stock and poultry waste dumped in Nigeria, this tag of poverty can be purged. It makes research sense to investigate the bio-transformation of this bio matter to biogas as a deliberate exertion to create wealth and meet the energy need of the Nation.

\section{Materials and Methods}

\subsection{Research Design}

This study adopted an experimental research design, involving a single batch fermentation of substrates (water hyacinth and poultry waste).

\subsection{Water Hyacinth Collection}

Eichhorniacrassipes species of the water hyacinth were collected from the Woji Creek, a freshwater creek in Port Harcourt, in Obio-Akpor Local Government Area of Rivers State. Poultry waste which served as the organic substrates in this study were collected from poultry farms situated within Port Harcourt metropolis.

The collection was done in the early hours of the morning in its fresh mature bases and transported to the Animal and Environmental Biology Department Laboratory, University of Port Harcourt for identification and preparation for the production of biogas.

\subsection{Water Hyacinth Preparation}

The water hyacinth Eichhorniacrassipes species was sliced into pieces and exposed to sun on a black polyethene material for an even drying of the entire aquatic plant, to reduce the water content, taken out at sunrise and back at sun set, this drying procedure was done for 14 days ( 2 weeks).

\subsection{Collection of Poultry Waste}

Freshly produced poultry wastes were collected from Maxzy Farms Limited, Rumuopirikon Community in ObioAkpor Local Government Area of Rivers State and transported in bowls to the Laboratory of Animal and Environmental Laboratory, University of Port Harcourt.

\subsection{Construction of Digester}

The digesters were locally fabricated using plastics and pipes purchased from the conventional building material market in Mile 3 Diobu, Port Harcourt, Rivers State. The digester major components are as described:

- Vent: An outlet of the digester that allows discharge of the spent sludge out of the system.

- Stirrer: the stirrer pipes that were blocked at both ends to a projection in the inner component of the digester.

- Inlet: the inlet unit, a large opening used a source of inoculation or loading.

- A thermometer: inbuilt thermometer to enable steady temperature check.

- Base tank: is the main stay of the substrates and contained the entire system.

Gas valve: the gas valve was connected through the component by a hose and a burner at the terminal.

\subsection{Culturing of Microbes}

\subsubsection{Procedure}

The medium nutrient broth was used to suspend bacteria (Bacillus spp. and Pseudomonas spp.). The medium was prepared according to manufacturer's directive by weighing $13 \mathrm{~g} / \mathrm{L}$ sterilized by autoclaving at 121 o $\mathrm{C}$ for $15 \mathrm{~min}$ and allowed to cool. Therefore, a loopful of the organisms (Bacillus spp. and Pseudomonas spp.) were inoculated separately into $1 \mathrm{~L}$ medium and inoculated at $37^{\circ} \mathrm{C}$ for $24-48$ hours.

Finally, the population was determined by plating on a freshly prepared nutrient agar medium from dilution $10^{-6}$ and the result obtained were indicated below:

Bacillus spp. $4.8 \times 10^{8} \mathrm{cfu} / \mathrm{ml}$

Pseudomonas spp. $3.6 \times 10^{8} \mathrm{cfu} / \mathrm{ml}$ 


\subsection{Inoculation}

The water hyacinth (dried) was weighed using a pan-top weighing balance scale. 3.8kg of water hyacinth weighed into 60 litres plastic containers and water in the ratio 1:2. It was mixed well and loaded into the digester. $2000 \mathrm{mls}$ of microbes was added to the system to catalyse and specifically digest the mixture.

The poultry wastes were weighed using a weighing scale. $8 \mathrm{~kg}$ of the waste was weighed and water added in the ratio of $1: 1$ by volume. al., 1992).

Initial temperature and $\mathrm{pH}$ of the system were recorded and daily readings charted in accordance with (Misra et

\subsection{Heat Efficiency and Cooking Rate Test}

The environmental temperature was measured using mercury-in-glass thermometer. The gases produced were passed through a rubber hose to the adjusted burner to determine the flammability and cooking rate of each of the gases. Cooking $(\mathrm{Cr})=$ Weight of substance $(\mathrm{kg})$ Time taken to boil (minutes)

Sasse (1988)

The time taken by the heat produced from the biogas to raise the temperature of $0.3 \mathrm{~L}$ of water to $100^{\circ} \mathrm{C}$ was also (heat efficiency) measured using a stop watch. The temperature of the heated water was determined by inserting a mercury-in-glass degree Celsius $\left({ }^{\circ} \mathrm{C}\right)$ thermometer into the water.

\subsection{Data Analysis}

Data generated were subjected to descriptive analysis using Statistical Package for Social Sciences (SPSS) software version 23.0. One way Analysis of variance (ANOVA) was used to compare statistical difference $(\mathrm{P}<0.05)$ for temperature, $\mathrm{pH}$ and biogas yield.

\section{Results}

The two organic substrates (poultry waste and water hyacinth) yielded gas in the digester, catalyzed by Bacillus spp. and Pseudomonasspp and the results obtained are presented in this chapter.

The mean cumulative temperature in the digester for the two substrates shows that the temperature in the digester ranged from $28^{\circ} \mathrm{C}-32^{\circ} \mathrm{C}$, with the digester containing poultry waste recording the utmost temperature of $32^{\circ} \mathrm{C}$, while the digester containing water hyacinth, had the uttermost temperature, $28^{\circ} \mathrm{C}$. Temperature fluctuations across the two digesters are presented in Figure 1 . Poultry waste had the utmost temperature fluctuations ranging from $29^{\circ} \mathrm{C}-32^{\circ} \mathrm{C}$. Poultry waste had its optimal temperatures on day 6, 7 and 11. Peak temperature of the two-digester increased as the retention time elapsed. Temperature fluctuations across the two substrates were significantly different $(\mathrm{P}<0.05)$.

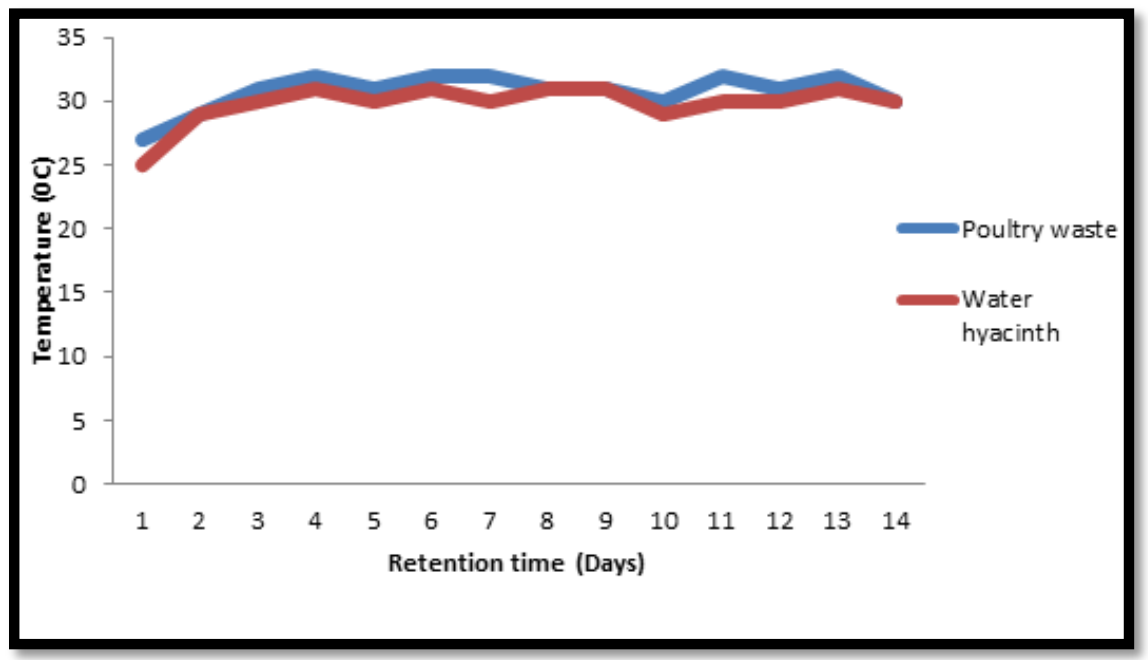

Figure 1: Cumulative Digester Temperature for the Two Substrates Digested

Routine $\mathrm{pH}$ check for the digester was also recorded using a portable $\mathrm{pH}$ meter. Figure 2 shows the $\mathrm{pH}$ value of the two substrates digested for a period of 14 days. The lowest $\mathrm{pH}$ value was 5.3. Poultry waste fluctuated with optimum $\mathrm{pH}$ value of 7.0 for days 2, 5, 7 and 12 with a slight decrease to 6.9 on day 8 . Water hyacinth digester maintained a slightly neutral balance for days 8 and 9 with $\mathrm{pH}$ value of 6.9. Both substrates recorded a neutral $\mathrm{pH}$ value on days 7 . The $\mathrm{pH}$ value for both digesters ranged from 7.0 (day 7) to 7.3 (day 13). pH fluctuations across the digester were not significantly different $(\mathrm{p}>0.05)$. 


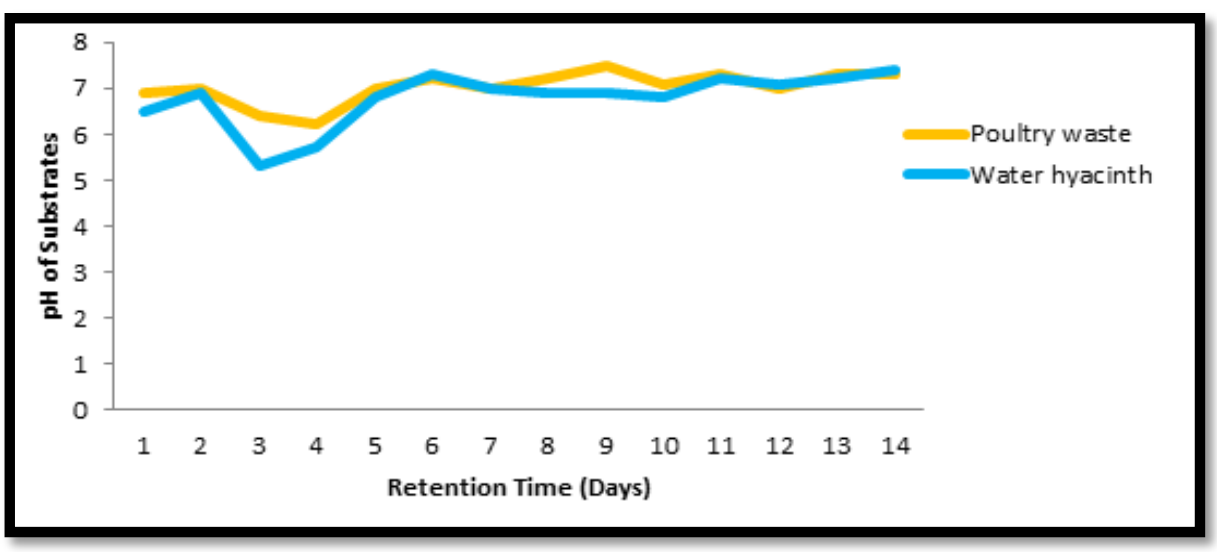

Figure 2: Cumulative Ph Changes for the Two Substrates Digested

The cumulative gas yield from poultry wastes is presented in Figure 3. The results showed that there was a steady increase in gas yield with slight fluctuations for poultry wastes from days 1 to 7 . There was a slight fall on day 10 ( $20.0 \mathrm{ml})$. The daily gas yield from poultry waste digester ranged from $4.0 \mathrm{ml}$ to $47.8 \mathrm{ml}$, the highest to the lowest values respectively. The highest gas yield occurred on day 12, while the uttermost yield occurred on day 1. Gas yield increased as retention time decreased.

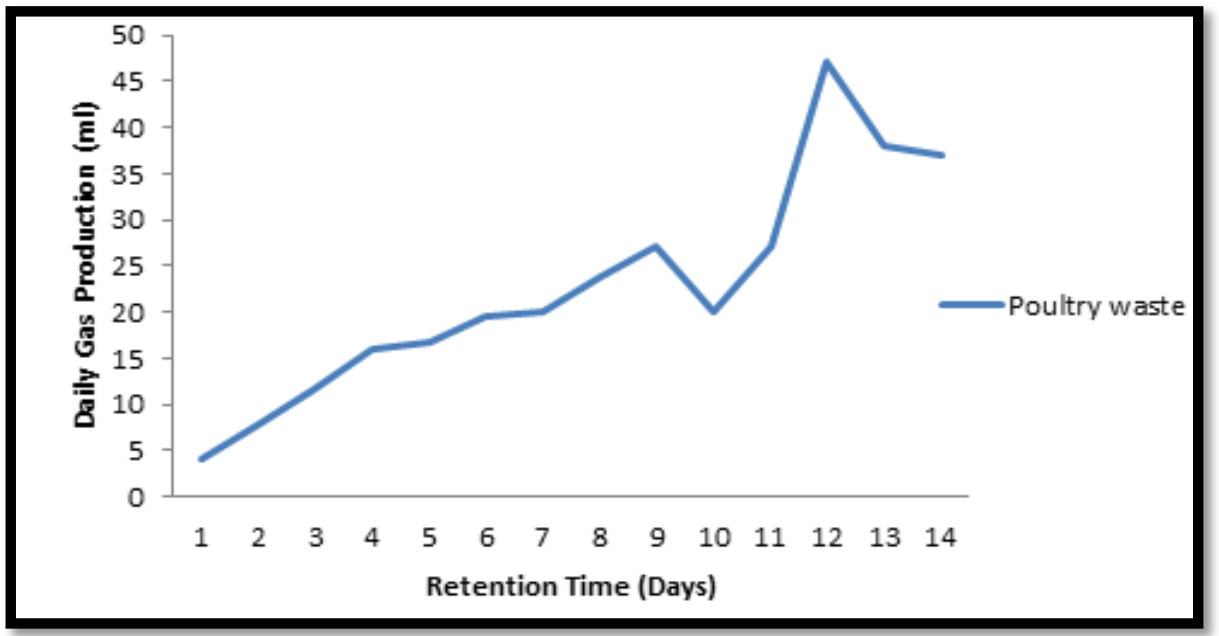

Figure 3: Cumulative Gas Yield from Poultry Digester

The cumulative gas yield from water hyacinth digester is presented in Figure 4. Gas yield was observed to be negligible between days 1, 2 and 3. Gas production ceased on day 4 and had a negligible increase between days 5 and 6 . Gas production started towards the end of day 6 with a rapid increase to $35.0 \mathrm{ml}$ on day 10 . There was a slight decrease between days 11 and 12 and it fluctuated increasingly between days 13 and 14 from $37.0 \mathrm{ml}$ to $32.0 \mathrm{ml}$ and started decreasing on day $14(32.0 \mathrm{ml})$.



Figure 4: Cumulative Gas Yield from Water Hyacinth Digester 
The comparisons of the cumulative gas yield of the two substrates digested are presented in Figure 5. The highest gas yield occurred in the poultry wastes $(47.0 \mathrm{ml})$ whereas; the digester containing the water hyacinth produced the lowest volume of gas $(37.0 \mathrm{ml})$. There was no sharp fall of gas yield in the digesters containing water hyacinth as digestion occurred except for decrease due to decrease in retention time. The gas produced by the two substrates had their start off at days 1 and 2, the daily gas yield across the digester decreased as the retention time elapsed. Poultry wastes maintained a slight uniform gas yield while water hyacinth fluctuated throughout the retention time.

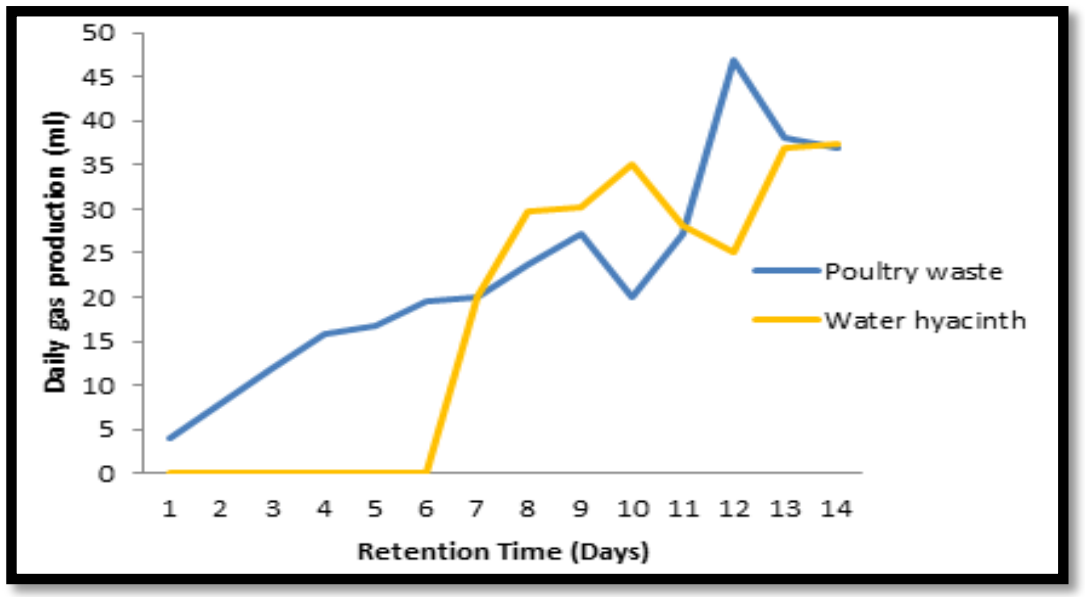

Figure 5: Cumulative Gas Production of the Two Substrates Digested

\subsection{Summary of Heat Efficiency and Cooking Rate for Biogas for Both Substrate and Control}

The summary of heat efficiency and cooking rate for the biogas production are presented in Table 1 . The gases produced were all subject to combustion using an adjusted biogas burner. Biogas produced by poultry dung had the highest heat efficiency (451seconds) while the lowest was from biogas produced by water hyacinth (513 seconds) the cooking rate of the substrates digested showed that poultry dung had $0.0350 \mathrm{~L} / \mathrm{min}$ was recorded for water hyacinth In comparison with conventional gas, the time taken to raise $0.3 \mathrm{~kg}$ of water to boiling point $\left(100^{\circ} \mathrm{C}\right)$ was $339 \mathrm{~seconds}$ which was higher than that recorded for water hyacinth and poultry dung.

\begin{tabular}{|c|c|c|c|}
\hline Substrate & Mean Time (Seconds) & Mean Time (Minutes) & Cooking Rate(kg/min) \\
\hline Water hyacinth & 513 & 8.56 & 0.0350 \\
\hline Poultry dung & 451 & 7.53 & 0.0398 \\
\hline Control (conventional gas) & 339 & 5.65 & 0.0530 \\
\hline
\end{tabular}

Table 3: Summary of Heat Efficiency and Cooking Rate for Biogas for Both Substrate and Control

\section{Discussion}

Temperature for fermentation greatly affects biogas production and can be produced within a wide range of temperature from psychrophilic $\left(<20^{\circ} \mathrm{C}\right)$, through mesophilic $\left(20-45^{\circ} \mathrm{C}\right)$ and thermophilic $\left(45-122^{\circ} \mathrm{C}\right)$ temperatures, though mesophilic and thermophilic temperature ranges are more favourable for anaerobes ((El- Mashad et al, 2004)). In this study, the temperature is between $25-32^{\circ} \mathrm{c}$ which confirms with mesophilic temperature range and this means that we can install digesters that will operate within this temperature range in our rural communities. The finding of this work is in tandem with the submission of Verma, 2002 who suggested that methanogens thrive best in mesophilic temperature range.

$\mathrm{pH}$ value indicates the degree of acidity or alkalinity of a solution which is important in anaerobic digester. In this study, the $\mathrm{pH}$ value was between the ranges of 6.5-7.4. The sharp drop on day 3 (Figure.2) could be attributed to low microbial activity, and methanogens do not activate on low $\mathrm{pH}$ medium. If slight acidification occurs during anaerobic digestion, the $\mathrm{pH}$ can be increased artificially by adding water or lime in the reactor (Netter et al., 1990). Lopes et al (2004) also reported maximum biogas yield from cattle dung at $\mathrm{pH}$ of 7 , which is within range of this study. According to (Schnürer and Jarvis, 2009), biogas processes usually run best at neutral pH values or slightly above neutral (pH between 7.0 and 8.5) and should be checked and adjusted by adding stabilising agents to make certain production runs efficiently.

From the results of comparison of the daily gas production from the two substrates, the peaks show the fluctuations in the quantity of gas yield for each digested substrate; possibly owing to variations in the environmental parameters. Digester containing poultry wastes released more gas than the water hyacinth digester. The highest volume of gas produced in a day was $47.0 \mathrm{ml}$. This implies that poultry waste produced more biogas than water hyacinth. This could mean that poultry waste has more nutrient content compared to water hyacinth; therefore, it can be deduced that poultry waste has more potential and provide more efficient means of biogas production.

The difference in the times taken to raise the water temperature to boiling point did not fluctuate significantly $(p>0.05)$ over the test period. This could be attributed to the influence of low environmental temperature. Another factor contributing to the slight variation in heat efficiency can also be attributed to the methane content of the biogas produced from the substrate. This conforms to the findings of Sasse (1988) which suggested that the combustibility of any biogas is a function of its methane content. 
The findings of the study revealed that the time taken to raise the temperature of water to boiling point ( $100^{\circ} \mathrm{C}$ ) was faster for conventional gas (control) when compared with poultry waste. Similarly, the findings of the study revealed that the time taken to raise the temperature of water to boiling point $\left(100^{\circ} \mathrm{C}\right)$ was faster for conventional gas (control) when compared with water hyacinth. In comparison with both substrates, poultry waste took lesser time to raise $0.3 \mathrm{~kg}$ of water to boiling point than water hyacinth. The methane content of poultry waste on the other hand can attributed to nature of organic waste present in the substrate which is also a function of the type of feed the birds were exposed to Sasse (1988). This agrees with the suggestion of Mandal et al., (1999), that the burning of biogas flame is a function of the change of methane composition. The biogas cooking rates were $0.0350 \mathrm{~kg} / \mathrm{min}, 0.0398 \mathrm{~kg} / \mathrm{min}$, and $0.0530 \mathrm{~kg} / \mathrm{min}$ for water hyacinth, poultry dung and control respectively. The burner was used to boil water as a confirmatory test of its performance.

\section{Conclusion}

Water hyacinths are proving too difficult to be eradicated completely because they rapidly adapt and regenerate upon perturbation. This research elucidates that some aquatic macrophytes like water hyacinth (Eicchorniacrasssipes) which has become a menace to fishing and fisheries activities can be converted to useful economic resources. This will help diversify our economy from a mono-economy to a diversified economy. Similarly, agricultural wastes such as poultry dung can also be transformed to a source of wealth. It can be utilized in biogas production as an alternative form of energy and another form of waste management.

\section{Recommendations}

- Further research can be carried out using other plant and animals wastes in producing gas for domestic use and commercial purposes.

- Government should diversify the source of energy from oil to agricultural wastes in order to create wealth and employment.

- For small scale production, low cost of designs (like use of water dispenser or drums) can be used to suit the adoption of biogas technology.

- In order to improve the efficiency and cooking rate of biogas to equal that of the conventional gas, characterization of the biogas should be carried out to reduce the impurities contained in the unprocessed biogas.

\section{References}

i. El- Mashad, H. G., Zeeman, W., Vanloon, A., Gerard, and Lettinga, G. (2004). Effect of temperature and temperature fluctuation on thermophilic anaerobic digestion of cattle manure. Biores. Tech. 95: 191-201.

ii. Liu, X., Chen, Y., Du, G. and Chen, J. (2008). Effects of organic matter and initial carbon nitrogen ratio on the bioconversion of volatile fatty acids from sewage sludge. Journal of Chemical Technology and Biotechnology. 83: 1049-1055.

iii. Lopes, W.S., Leite, V.D and Prasad, S. (2004). Influence of inoculum on performance of anaerobic reactors for treating municipal solid waste. Bioresour.Technol 94:261-266.

iv. MandalT, Kiran B.A and MandalNk (1999). Determination of the quality of biogas by flame temperature measurement, Energy, Conservation \& Management 40: 1225-1228.

v. Misra, I.M., Ghazi, T.I.M and Omar, R. (1992). Anaerobic digestion technology in livestock manure treatment for biogas production: A review. Eng. Life Sci.12(3): 258-269.

vi. Netter, R. and Bischofsberger, W. (1990): Sewage treatment by planted soil filters. inp.f cooper, b.cfindlater (Eds.): Constructed Wetlands in Water Pollution Control: Pergamon, pp. 525-528.

vii. Oladeji, J., Enweremadu, C., and Olafimihan, E. (2009). Conversion of Agricultural Residue into Biomass Briquettes.IJAAAR. 5(2): 116-123.

viii. Rezania, H.R., Sidkey, N.M., Elsoud, M.M.A., Hamouda, H.I and Elazzazy, A.M. (2015). Bioethanol production from water hyacinth hydrolysate by Candida tropicalisY-26. Arab. J. Sci. Eng. 44: 33-41.

ix. Sasse, L. (1988). Biogas plants; a Publican of the DeutschesZentrum fur Entwicklungstechnologian - GATE in: Deutsche Gesellschaft fur TechnischeZusammerarbeit (GTZ) GmbH.

x. Schnürer A. and Jarvis, Å. (2009). Microbiological Handbook for Biogas Plants. Swedish Waste Management U2009:03. Swedish Gas Centre Report 207.

xi. Sutarti, R.; Abdelaziz, E. A.; Demirbas, A.; Hossain, M. S. and Mekhilef, S. (2011): A review on biomass as a fuel for boilers. In Renewable and Sustainable Energy Reviews.15 (5): 2262-2289.

xii. Verma, S. (2002). Anaerobic Digestion of Biodegradable Organics in Municipal Solid Wastes. Unpublished M.Sc. Thesis, Department of Earth and Environmental Engineering, FU Foundation School of Engineering \& Applied Science, Colombia University. 